\title{
Chromium isotope systematics and diagenesis in marine carbonates
}

Changle Wang ${ }^{1,2}$, Kyle S. Rybacki ${ }^{3,4}$, Dalton S. Hardisty $^{5}$, Xiangli Wang ${ }^{6,7}$, Christopher T. Reinhard ${ }^{3}$ AND Noah J. Planavsky ${ }^{2}$

${ }^{1}$ Key Laboratory of Mineral Resources, Institute of Geology and Geophysics, Chinese Academy of Sciences, Beijing,

China(wangcl@mail.iggcas.ac.cn)

${ }^{2}$ Department of Geology and Geophysics, Yale University, New Haven, CT, USA(noah.planavsky@yale.edu)

${ }^{3}$ School of Earth and Atmospheric Sciences, Georgia Institute of Technology, Atlanta, GA, USA

${ }^{4}$ Bureau of Land Management, Phoenix, AZ, USA

${ }^{5}$ Department of Earth and Environmental Sciences, Michigan State University, East Lansing, MI, USA

${ }^{6}$ Department of Marine Sciences, University of South Alabama, Mobile, AL, USA

${ }^{7}$ Dauphin Island Sea Lab, Dauphin Island, AL, USA

Stable chromium (Cr) isotopes have emerged as a new tool for tracking broad-scale changes in Earth's surface oxygen levels. Carbonates are one proposed sedimentary $\mathrm{Cr}$ isotope archive. In order to provide a more robust framework for interpreting carbonate $\mathrm{Cr}$ isotopic compositions and evaluating their ability to record the global redox state, we explored $\mathrm{Cr}$ isotope systematics of modern and Archean carbonate successions. We studied carbonate platform sediments from the Great Bahama Bank with variable diagenetic histories to better understand the effects of diagenetic alteration on carbonate-bound $\mathrm{Cr}$ and its isotopic composition in a modern well-oxygenated ocean-atmosphere system. More specifically, we investigated the effects of dolomitization and aragonite-to-calcite neomorphism in marine and meteoric fluids. We additionally present $\delta^{53} \mathrm{Cr}$ values from three carbonate successions, the $\sim 3.0$ Ga Chobeni, $\sim 2.8$ Ga Mosher Carbonate, and $\sim 2.65$ Ga Cheshire formations, that were deposited under an anoxic atmosphere. We find that modern Bahamian carbonates have a large range of almost exclusively positive $\delta^{53} \mathrm{Cr}$ values that appear to be reset during both meteoric and marine diagenesis. Moreover, we find that Archean carbonate successions - like the mid-Proterozoic successions - contain both positively fractionated and crustal $\delta^{53} \mathrm{Cr}$ values. The $\mathrm{Cr}$ isotope fractionation observed in the Archean could be linked to either non-redox dependent $\mathrm{Cr}$ isotope fractionations, local $\mathrm{Cr}$ redox cycling, late-stage diagenetic alteration, or some combination thereof. Given these effects, we suggest that $\mathrm{Cr}$ isotope values from ancient carbonate sediments should be interpreted with extreme caution and should not be linked to periods of atmospheric oxygenation. 